\title{
Insights Into Vacuum Preloading Consolidation of Landfill Sludge Based on Fe2+-activated Sodium Persulfate
}

\section{Yajun Wu}

Shanghai University

Xingtao Zhang

Shanghai University

Xudong Zhang ( $\nabla$ xdzhang@shu.edu.cn )

Shanghai University

haiqiang Zhang

Shanghai University

Yaoyi Wang

Shanghai University

Peng Ye

Shanghai University

\section{Research Article}

Keywords: Landfill sludge preconditioning, Sodium persulfate, Vacuum preloading, Water content, Particle size

Posted Date: October 15th, 2021

DOl: https://doi.org/10.21203/rs.3.rs-908421/v1

License: (c) (1) This work is licensed under a Creative Commons Attribution 4.0 International License. Read Full License

Version of Record: A version of this preprint was published at Environmental Science and Pollution Research on January 21st, 2022. See the published version at https://doi.org/10.1007/s11356-02218657-6. 


\section{Abstract}

To further reduce the in-situ sludge from landfill, $\mathrm{Fe}^{2+}$-activated sodium persulfate combined with vacuum preloading was first proposed. Firstly, the effects of optimal $\mathrm{Na}_{2} \mathrm{~S}_{2} \mathrm{O}_{8}$ dosage on the landfill sludge (LS) were investigated by the vacuum filtration experiments. Then, vacuum preloading experiments were conducted on the sludge with different $\mathrm{Na}_{2} \mathrm{~S}_{2} \mathrm{O}_{8}$ dosage to study the water content, water discharge and settlement. Besides, sludge particle size diversification was carried out by particle size distribution and scanning electron microscopy (SEM) tests. The results were summarized as follows: the specific resistance of filtration (SRF) of LS could be reduced by $98.5 \%$ mostly when the $\mathrm{Na}_{2} \mathrm{~S}_{2} \mathrm{O}_{8}$ dosage was $30 \%$; the particle size became significantly smaller, and large particles were converted to small particles; the water content dropped from $86.9 \%$ to $58.3 \%$; the SEM test manifested the oxidation of sodium persulfate caused the destruction of the glial structure of the sludge and the recombination of partial particles.

\section{Introduction}

With the rapid growth of modern society and economy, there exists numerous municipal sewage sludge (Shi et al., 2015; Wu et al., 2020). The treatment of sewage sludge has brought considerable costs to the operation of these facilities (Becerra et al., 2010). Generally speaking, agricultural utilization, dry incineration, landfill, construction materials utilization and soil remediation are the main sludge handling ways (Wu et al., 2019; Wu et al., 2021b). Among them, landfilling of sludge is considered an extremely inefficient treatment method, which is listed as the lowest priority in Europe and prohibited in lots of countries (Alami et al., 2019; Wu et al., 2020). Sanitary sludge landfill is widely applied in China due to its strengths of easy operation and low price (Wu et al., 2021b; Yang et al., 2015). Yet, the high moisture content (about $75 \%$ to $85 \%$, wet basis) of landfill sludge (LS) occupies valuable land resources, leading to numerous cities unable to find landfills (Xu Y. et al., 2021). Furthermore, China's sludge output will stupendously attain 100 million tons by 2025 (Li, 2020).

Besides, it is well known that deep dewatering of sludge is an essential process for sludge handling and disposal (Shi et al., 2015). Generally speaking, the difficulties in sludge dewatering can be caused by its highly compressible characteristics and high organic content, and contain many microorganisms and impurities (Mowla et al., 2013; Raynaud et al., 2012; Yang et al., 2015). The essence of deep dewatering is to destroy the flocculent structure of EPS, change the particle size, floc structure and water storage state (Sheng et al., 2010). To realize the objective of deep dewatering and reducing the volume of LS, numerous methods have been applied to facilitate the dewatering efficiency of sewage sludge in recent years, such as chemical (Lin et al., 2014), freeze-thaw (Wu et al., 2020; Zhang et al., 2021b), thermal (Ruan et al., 2021), electrolysis(Yuan et al., 2011) and ultrasonication (Feng et al., 2009). Among them, chemical conditioning possesses the following advantages: low cost, convenient operation, and remarkable dewatering effect (Xu Y. et al., 2021). Thence, chemical conditioning becomes the most widely used sludge pretreatment method (Hoadley et al., 2011). Currently, deep dewatering of sludge 
often adopts the plate and frame filter press method. This method requires digging out the sludge from landfills and pre-processing, which has certain issues of high cost, complicated procedures and even causes secondary environmental pollution (Wu,Tang, et al., 2018a; Wu et al., 2020). Hence, finding an economical, environmentally friendly and pollution-free method for LS is extremely urgent (Wu,Lin, et al., 2018a; Wu et al., 2020).

The vacuum preloading method is a method for deep dewatering of sludge (Wu,Lin, et al., 2018a; Wu et al., 2021b; Wu et al., 2020; Zhan et al., 2013), which has the advantages of large processing capacity, low cost, safety and reliability. Besides, a novel way that combines chemical preconditioning and vacuum preloading for landfill sludge handling has demonstrated excellent performance (Wu, Lin, et al., 2018a; Wu et al., 2021b). For instance, Zhan et al. (2013) discussed the feasibility of vacuum preloading treatment of sludge. The test results expressed that the sludge water content significantly reduced, and the strength increased a little. Besides, Zhan et al. (2015) combined the vacuum preloading method with $\mathrm{FeCl}_{3}$ for the first time. The sludge volume reduction exceeded $40 \%$, showing the superiority of the experimental effect. What's more, Lin et al. (2014) used vacuum pre-compression assisted chemical conditioning $\left(\mathrm{FeCl}_{3}\right)$ to conduct a pilot experiment on LS. The results showed that the average consolidation degree increased by $70.9 \%$, and the total sludge volume decreased by $47.5 \%$ after vacuum preloading for $3.2 \mathrm{~m}$ thick sludge pits, but the increase in strength was not obvious. In addition, Wu et al. (2020) combined freeze-thaw pretreatment and vacuum preloading to treat landfill sludge. The results indicated that the volume reduction of sludge reached $57.1 \%$, the unconfined compressive strength was significantly increased, and the water content was decreased from $73.4 \%$ to $53.7 \%$. Furthermore, works focused on Fenton combined vacuum preloading treatment of sludge have also been researched correspondingly (Wu,Lin, et al., 2018a; Wu et al., 2021b).

As a new type of advanced oxidation technology, sodium persulfate reagent has strong oxidation ability (Ahmad et al., 2013) and possesses broad application prospects in sludge treatment (Wu et al., 2021c). The typical advanced oxidation processes technology for activated persulfate oxidation is dependent on $\left(E_{0}=2.5-3.1 \mathrm{~V}\right)$ (Ren et al., 2015; Wei, Xia, et al., 2020), which can break down sludge organic matter and destroy the EPS structure (Ahmad et al., 2013). The advantages of persulfate can be attributed to safer, easier storage and transport (Zhou et al., 2015). In addition, persulfate itself has specific oxidizing properties, but its oxidizing capacity is limited. In general, persulfate can be activated to generate in the situation alkali, activated carbon, heat, light and transition metals $\left(\mathrm{Fe}^{2+}, \mathrm{Mn}^{2+}, \mathrm{Cu}^{2+}\right.$, etc.) (Cai et al., 2015), in which $\mathrm{Fe}^{2+}$ contains the following characteristics of simple operation, low toxicity and price, as well as environmentally friendly nature (Cai et al., 2015). Thus, $\mathrm{Fe}^{2+}$ is often used to activate persulfates, and the main activation reaction equation (1) is as follows (Wu et al., 2021c).

$$
\mathrm{S}_{2} \mathrm{O}^{2-}+\mathrm{Fe}^{2+} \rightarrow \cdot \mathrm{SO}_{4}^{-}+\mathrm{Fe}^{3+}+\mathrm{SO}_{4}^{2-}
$$

At this stage, significant efforts have been made to use activated persulfate to achieve deep dewatering of sludge. A study by Zhen et al. (2012) concluded that Fe ${ }^{2+}$-activated persulfate oxidation could enhance 
the dewaterability of sludge, which could induce the release of EPS-bound water and bound water in microbial cells. In addition, Shi et al. (2015) employed $\mathrm{Fe}^{2+}$-activated sodium persulfate combined with thermal-pretreated phosphor-gypsum for sludge conditioning and deep dewatering, investigated the synergetic effects and mechanism of the composite conditioners. What's more, the consolidation characteristics of sludge treated by $\mathrm{Fe}^{2+}$-activated sodium persulfate (Wu et al., 2021c) was studied, and the consolidation coefficient of sludge was greatly improved.

Thus, it appears that previous studies on sludge have focused on fresh sludge, and most of the works have concentrated on the decomposition of sludge's EPS. Few papers have provided a perspective on the effect of $\mathrm{Fe}^{2+}$-activated $\mathrm{Na}_{2} \mathrm{~S}_{2} \mathrm{O}_{8}$ combined with vacuum preloading for deep dewatering of sludge. Therefore, $\mathrm{Fe}^{2+}$-activated $\mathrm{Na}_{2} \mathrm{~S}_{2} \mathrm{O}_{8}$ assisted vacuum preloading was first proposed. First of all, the SRF experiment was carried out to obtain the optimal addition amount of $\mathrm{Na}_{2} \mathrm{~S}_{2} \mathrm{O}_{8}$. Then, according to the outcomes of the SRF experiment, a vacuum preloading model experiment was carried out. Five groups of different $\mathrm{Na}_{2} \mathrm{~S}_{2} \mathrm{O}_{8}$ dosage were applied to study the effect on the vacuum consolidation through indicators such as water discharge, water content, settlement and volume reduction ratio, etc. Moreover, the particle analysis examination and SEM experiment of LS conditioned by $\mathrm{Fe}^{2+}$ activated $\mathrm{Na}_{2} \mathrm{~S}_{2} \mathrm{O}_{8}$ were analyzed from a microscopic point of view. The flowchart of this research was shown in Fig. 1.

\section{Material And Methods 2.1. Sludge samples}

As shown in Fig. 2, the LS samples in this study were obtained from the Bailonggang Wastewater Treatment Plant of the Changjiang River in Shanghai, China. A single sludge landfill site covers 180 meters long, 100 meters wide and 6-8 meters deep (Wu et al., 2020), which occupies lots of land resources. Generally speaking, sewage sludge is produced in the primary sedimentation tank of a sewage treatment plant, and its composition is complex and contains a lot of water (75\%-85\%) (Xu Y. et al., 2021) . Besides, landfill sludge has been landfilled in a landfill for more than ten years. Therefore, carrying out deep dehydrate and capacity decrease with the landfill sludge is extremely urgent. According to CJ/T2492007 (2007), the density is measured by the ring knife (4 cm high) method, the water content is measured by drying to a constant weight in a controlled oven $\left(60^{\circ} \mathrm{C}\right.$ to $\left.70^{\circ} \mathrm{C}\right)$, and the organic content is measured by burning at a high temperature to $550^{\circ} \mathrm{C}$, and the basic characteristic of LS is presented in Table 1 . What's more, the chemical composition of the sludge can be found in our previous study (Wu et al., 2021c).

Table 1 Characteristic of landfill sludge. 


\begin{tabular}{|c|c|c|c|c|c|c|}
\hline Item & $\mathrm{W}_{\mathrm{c}}(\%)$ & Gs & $P\left(\mathrm{~g} / \mathrm{cm}^{3}\right)$ & $0_{c} \nabla \% \square$ & $\mathrm{pH}$ & 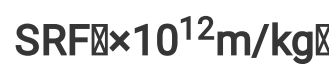 \\
\hline $\begin{array}{l}\text { Landfill } \\
\text { sludge }\end{array}$ & 86.9 & 2.32 & 1.12 & 34.3 & 8.0 & 11.34 \\
\hline
\end{tabular}

In which: $\mathrm{W}_{\mathrm{C}}$ is the water content; $\mathrm{Gs}$ means $\mathrm{t}$ specific density; $\mathrm{O}_{\mathrm{C}}$ denotes the organic matter content.

\subsection{Experiment materials}

The dewatering performance of $\mathrm{Fe}^{2+}$-activated sodium persulfate on sludge shows that the dosage of $\mathrm{S}_{2} \mathrm{O}_{8}{ }^{2-}$ and the molar ratio of $\left(\mathrm{Fe}^{2+} / \mathrm{S}_{2} \mathrm{O}_{8}{ }^{2-}\right)$ are the two main elements that advance the dehydration of sludge (Guan et al., 2011; Wei,Xia, et al., 2020; Zhen et al., 2012). And our previous studies have shown that the optimal molar ratio of $\mathrm{n}\left(\mathrm{S}_{2} \mathrm{O}_{8}{ }^{2-}\right) / \mathrm{n}\left(\mathrm{Fe}^{2+}\right)$ for $\mathrm{LS}$ used in this experiment is 1.0 (Wu et al., 2021c). Therefore, four control groups were used for the vacuum filtration experiments and vacuum preloading tests: $10,20,30,40 \% \mathrm{Na}_{2} \mathrm{~S}_{2} \mathrm{O}_{8}$ of the dry solids content of sludge and original sludge. To avoid errors, two parallel groups were set up for each experimental group.

\subsection{Experimental equipment and procedures}

\subsubsection{Vacuum filtration experiment}

When exploring the dewatering performance of sludge, SRF is usually used as a comprehensive index to assess the dewatering capability of sludge. The SRF refers to the hindrance per unit filtration proportion of sludge per unit mass at specific stress. The lower the SRF, the better the dewaterability and vice versa (Lo et al., 2001). The SRF calculation formula is shown in equation (2):

$$
\mathrm{SRF}=\frac{2 \mathrm{PA}^{2} \mathrm{~b}}{\mu \omega}
$$

In which: $P$ is the filtration pressure $(\mathrm{kg} / \mathrm{m})$; $b$ means the slope of the linear equation $t / v=b \times v+a$ ( $t$ is the time, $v$ represents the volume of the filtrate); $A$ is the filtration area $\left(\mathrm{m}^{2}\right) ; \omega$ represents the dry solid retained on the filter medium by filtering a unit volume of filtrate weight $(\mathrm{kg} / \mathrm{m}) ; \mu$ denotes the dynamic viscosity $\left(\mathrm{kg} / \mathrm{s} / \mathrm{m}^{2}\right)$.

The device for measuring the SRF of sludge is mainly shown in Fig. 3(a), composed of Buchner funnel, Erlenmeyer flask, Catheter, Vacuum gauge and Vacuum pump, etc. The test records the vacuum filtration time and the corresponding filtrate volume of the sludge during the suction filtration dehydration process.

\subsubsection{Vacuum preloading experiment}


To research the effect of sodium persulfate addition on the vacuum dewatering of landfill sludge, a model test of $\mathrm{Fe}^{2+}$-activated sodium persulfate combined with vacuum preloading was conducted on the sludge based on the SRF test, and the feasibility of combined treatment of $\mathrm{Fe}^{2+}$-activated sodium persulfate and vacuum preloading was verified, as shown in Fig. 3. (b).

The equipment of vacuum preloading test mainly includes Cylindrical model box, Drain pipe, Sealing caps, Vacuum conversion, Valve, Vacuum gauge and Vacuum pump, etc. A cylindrical model box with an inner diameter of $10 \mathrm{~cm}$ and a height of $40 \mathrm{~cm}$ and sealing caps adopts a $2 \mathrm{~cm}$ thick hard plexiglass plate with a sealing ring around it. Cylindrical model box with holes at the top and bottom, both top and bottom covered with non-woven geotextile. Experimental procedure using single-sided drainage.

The experiment was divided into five groups; each group of sludge dosage was $1800 \mathrm{~g}$, different additions of sodium persulfate reagents were added $\left(10,20,30\right.$ and $\left.40 \% \mathrm{Na}_{2} \mathrm{~S}_{2} \mathrm{O}_{8}\right)$; and set a group of original sludge ( $0 \%$ dosage) as a comparison. During the experiment, the drainage, sedimentation, and vacuum were monitored. When the water output is less than 2-4 $\mathrm{ml}$ per hour, stop the test. After the test, the unconfined compressive strength (UCS), SEM, and water content test of the sludge were carried out.

\subsubsection{Particle size experiment}

Before the vacuum preloading experiment, sludge samples with $0,20,30$ and $40 \% \mathrm{Na}_{2} \mathrm{~S}_{2} \mathrm{O}_{8}$ were analyzed for particle size. The sludge is a highly water-absorbing substance.

Due to the high content of organic matter in sludge, traditional geotechnical screening methods are not suitable for particle analysis of sludge (Wu et al., 2021b). Therefore, this particle analysis experiment employs a laser particle size analyzer for testing. According to the regulations of soil particle size, the sludge particle size consists of four groups, sand group (2-0.075 mm), silty group $(0.075-0.005 \mathrm{~mm})$, clay group (0.005-0.002 mm) and colloidal group (< $0.002 \mathrm{~mm}$ ) (Wu et al., 2021b).

\section{Results And Discussion}

\subsection{Vacuum filtration test results}

\subsubsection{The effect of sodium persulfate addition and pH on SRF}

According to equation (2), the connection between the dose of $\mathrm{Na}_{2} \mathrm{~S}_{2} \mathrm{O}_{8}$ and the SRF of LS can be obtained, as shown in Fig. 4(a). Besides, on the basis of the SRF's value of the sludge, its dewaterability can be divided into three grades. It includes easy dehydration $\left(<5.0 \times 10^{12} \mathrm{~m} / \mathrm{kg}\right)$, moderate grades $(0.5-$ $\left.1.0 \times 10^{13} \mathrm{~m} / \mathrm{kg}\right)$ and difficult dewaterability $\left(>1.0 \times 10^{13} \mathrm{~m} / \mathrm{kg}\right)($ Wu,Lin, et al., 2018a; Wu et al., 2021b).

The SRF of the non-conditioned sludge reached the maximum, $1.1 \times 10^{13} \mathrm{~m} / \mathrm{kg}$, which still belonged to the category of difficult dewaterability. However, after preconditioning, the SRF decreased with an increase of sodium persulfate reagent within a specific range. Among them, the SRF of $30 \% \mathrm{Na}_{2} \mathrm{~S}_{2} \mathrm{O}_{8}$ dosage 
reached $1.64 \times 10^{11} \mathrm{~m} / \mathrm{kg}$, only constituting $1.41 \%$ of the unconditioned sludge, and the sludge dewatering capacity was significantly promoted, matching the standard of easy dehydration. When the dosage of $\mathrm{Na}_{2} \mathrm{~S}_{2} \mathrm{O}_{8}$ was less than $30 \%$, the SRF decreased rapidly with the increasing $\mathrm{Na}_{2} \mathrm{~S}_{2} \mathrm{O}_{8}$, which demonstrated that the dewaterability of sludge had been dramatically accelerated. When the dosage was greater than $30 \%$, the value of SRF increased a little, and its dewaterability has begun to deteriorate. Besides, the outcomes also revealed that the highest SRF reduction efficiency could be reduced by around $98.5 \%$ at the dosage of $30 \% \mathrm{Na}_{2} \mathrm{~S}_{2} \mathrm{O}_{8}$, as shown in Fig. 4(a).

Besides, plotting the connection between the $\mathrm{pH}$ and the dosage of sodium persulfate of the sludge samples, as expressed in Fig. 4(b). As the pH value dropped from 8.0 to approximately 3.0, the SRF reduction efficiency increased significantly, with a maximum of $98.5 \%$, which indicated that $\mathrm{Fe}^{2+}$ activated sodium persulfate posed a powerful effect on the disintegration of sludge samples (Chen et al., 2001; Ruan et al., 2021).

\subsubsection{Organic matter content and water content}

The relationship between the organic matter content and $\mathrm{Na}_{2} \mathrm{~S}_{2} \mathrm{O}_{8}$ dosage was revealed in Fig. 4(c). The organic content decreased with the increase of $\mathrm{Na}_{2} \mathrm{~S}_{2} \mathrm{O}_{8}$ content. On the whole, the distribution of organic matter is relatively even. Compared with the unconditioned sludge, the organic content of conditioned sludge was slightly decreased, from $34.3 \%$ to $29.3 \%$. The possible reason for these notices might be attributable to the high oxidizing properties of , which could degrade most organic matter theoretically (Johnson et al., 2008). Besides, the water content of the sludge after vacuum filtration was measured, as shown in Fig. 4(d). The water content of the original sludge was reduced from $86.9 \%$ to $85.0 \%$, with a few changes in water content, which presented a difficult dewaterability performance. After preconditioning, the water content dropped significantly than that of the original sludge, in which the water content of each sludge sample (containing $10,20,30$ and $40 \%$ sodium persulfate reagent) reached $80.5 \%, 77.2 \%$, $76.0 \%$ and $76.7 \%$, respectively. The changes in water content were consistent with the change of the SRF, and the curve first decreased and then increased with the increase of the $\mathrm{Na}_{2} \mathrm{~S}_{2} \mathrm{O}_{8}$ dosage. However, it should be pointed out that the water content of the sludge remained more than $75 \%$, so a further step of dewatering was needed. Furthermore, as described in Fig.4(c) and Fig. 4(d), the water content increased with the increasing of organic matter content. On the other hand, the organic content of each sludge sample (with $10,20,30$ and $40 \%$ sodium persulfate reagent) was $32.5 \%, 30.8 \%, 29.6 \%$ and $29.3 \%$. The relationship between organic content and water content was a roughly positive correlation.

\subsubsection{Variation in sludge particle size}

The sludge particle size is an important indicator reflecting the microstructure of sludge. The relationship between sodium persulfate dosage and sludge particle size is shown in Fig. 5(a). After Fe ${ }^{2+}$ activated $\mathrm{Na}_{2} \mathrm{~S}_{2} \mathrm{O}_{8}$ preconditioning, the cumulative distribution curve of LS with different dosage is significantly moved upwards compared to the unconditioned sludge, indicating a reduction in sludge particle size. Among them, the curve of $30 \%$ dosage moved most evidently. Overall, there was a decrease 
in large particles and an increase in small particles of the sludge. The measured data of non-conditioned sludge showed that the proportion of sludge particles more than $0.075 \mathrm{~mm}$ was $51.8 \%$, much higher than that of conditioned sludge (varies from $31.9 \%$ to $36.3 \%$ ); the proportion of particles in the range of $0.002-$ $0.005 \mathrm{~mm}$ was $2.4 \%$ slightly lower than conditioned sludge (approximately $4.50 \%$ ), and the proportion of colloidal particles less than $0.002 \mathrm{~mm}$ was only $1.0 \%$, which was also lower than the treated sludge. Therefore, the following conclusions could be drawn: the strongly oxidizing properties of sodium persulfate after $\mathrm{Fe}^{2+}$-activated $\mathrm{Na}_{2} \mathrm{~S}_{2} \mathrm{O}_{8}$ led to the rupture of the EPS, which resulted in the reorganization of the particle size (Kim et al., 2016; Zhen et al., 2012), as well as the subsequent release of the bound water (Luo et al., 2018), sludge particles were oxidised and broken down into smaller particles (Li et al., 2017; Ruan et al., 2021). Furthermore, the particle size distribution of LS was inconsistent with the research of Zhang et al. (2020). Zhen et al. (2012) pointed out that the different origins of sludge, handling procedure and sludge kinds could explain these views. The LS taken from the surface layer has been buried in the reservoir area temporarily, and the degradation time was short. Consequently, large particles failed to be broken down into small particles.

On the other hand, from the particle group curve in Fig. 5(b), the peak of the sludge particle size (where the main distribution of sludge particles) shifted to the right after the $\mathrm{Fe}^{2+}$-activated sodium persulfate, and the particle size corresponding to the largest proportion decreased, which explained the strong oxidizing property of $\mathrm{Fe}^{2+}$-activated sodium persulfate. The particle size of $60 \mu \mathrm{m}$ with the original sludge was reduced and changed into smaller particles with a size of $20 \mu \mathrm{m}$ to $30 \mu \mathrm{m}\left(30 \% \mathrm{Na}_{2} \mathrm{~S}_{2} \mathrm{O}_{8}\right)$ from the percentage curve of particle size. In addition, the particle size of LS was mostly centralized in the sand and silty groups, demonstrating that agglomerates of large particles transformed into small particles (Ruan et al., 2021).

\subsection{Vacuum preloading experiment}

\subsubsection{Vacuum level}

The vacuum level variety during the suction filtration process is shown in Fig. 6(a). Some experiment groups leaked in the model box during the experiment, and the vacuum degree fell below $70 \mathrm{kPa}$. After sealing and plugging measures were taken, the vacuum degree returned to a normal state. The vacuum degree of the remaining experiments and the control group was stable at 70-80 $\mathrm{kPa}$ during the entire vacuuming process, which created a good condition for the experiment. Furthermore, within $0-4 \mathrm{~h}$, the vacuum degree of $30 \%$ and $40 \%$ samples fluctuated greatly, which may be caused by the discharge of a large amount of water.

\subsubsection{Total water output and drainage speed}

The total water output was collected and measured through the suction filter bottle. The curve of the water output and the drainage rate with the time was established, as presented in Fig. 6(b) and Fig. 6(c), respectively. It could be found that the drainage speed was remarkably affected by the level of 
vacuum (Wu,Lin, et al., 2018a) (as shown in Fig. 6(a) and Fig.6 (c)), and fluctuated with the fluctuation of the vacuum pressure, but the overall trend was downward. What's more, the water discharge increased with the increasing of $\mathrm{Na}_{2} \mathrm{~S}_{2} \mathrm{O}_{8}$. The water discharge process summarily could be consisted of three stages.

Phase $\otimes(0-4 h)$ was a rapid draining stage, in which the water output of the experimental group had the fastest increase, and the corresponding drainage rate changed rapidly, as shown in Fig. 6(b) and Fig. 6(c). Furthermore, at this stage, the cumulative water output of each sludge sample (containing $0,10,20,30$ and $40 \%$ sodium persulfate reagent) was $89,208,522,873$ and $847 \mathrm{ml}$, individually. Among them, the cumulative water output of $30 \%$ was $873 \mathrm{ml}$, much higher than the original sludge (less than $90 \mathrm{ml}$ ), accounting for about $60 \%$ of the total water output. This may be caused by the fact that the conditioned sludge was left to stand, and a large amount of supernatant was quickly discharged through the drain pipe under the behavior of vacuum stress, which could release a lot of bound water (Wu et al., 2020), and the permeability coefficient increased by $1 \sim 2$ orders of magnitude, subsequently significantly improving drainage efficiency (Ruan et al., 2021).

The second phase (about 4-24 h) was smooth, in which the drainage rate was slightly lower than the first stage. Meanwhile, the cumulative water output of this stage was significantly smaller than that of the first stage. The drainage process of the original sludge reaches stability and no more drainage. At this stage, the drainage capacity of the conditioned sludge reached approximately $95 \%$ to $98 \%$ of the total drainage capacity. The drainage rate and water discharge in the third stage (about 24-40 h) was extremely slow, in which the rate of water was less than $2-4 \mathrm{ml} / \mathrm{h}$. The drainage rate reached the minimum, and the dewatering effect further deteriorated (Wu et al., 2020).

Overall, during the entire phase of vacuum preloading, the drainage rate of the non-conditioned sludge was much lower than the experimental group. Therefore, the outcomes showed that the water output of the experimental group using $\mathrm{Fe}^{2+}$-activated sodium persulfate was much larger than unconditioned sludge, particularly with the $30 \%$ group. Among them, the maximum water discharge was close to 1500 $\mathrm{ml}$. In comparison, the non-conditioned sludge effluent volume was less than $100 \mathrm{ml}$. The former was 15 times more than the latter, indicating that the effect of $\mathrm{Fe}^{2+}$-activated $\mathrm{Na}_{2} \mathrm{~S}_{2} \mathrm{O}_{8}$ combined with vacuum preloading was significantly better than ordinary vacuum preloading. The explanation was in the following aspects: the sludge contained high organic matter content (Wu et al., 2021b) and low permeability coefficient (Wu,Lin, et al., 2018a); the EPS of untreated sludge was difficult to crack at the function of vacuum stress; the water was stored in the cells, and the sludge was densely agglomerated and packaged tightly. All of these caused difficulties in solid-liquid separation of non-conditioned sludge.

\subsubsection{Settlement and volume reduction ratio}

In general, the faster the sludge settles, the higher the sludge discharge and the better the dewatering. The curve of sludge settlement changing with time during the vacuum preloading experiment was shown in Fig. 6(d). After Fe $\mathrm{e}^{2+}$-activated sodium persulfate sodium, the sludge settled fast in the early stage, and the 
settlement gradually tended to be gentle with the decrease of the drainage rate in the later stage. The changing trend of settlement over time was roughly the same as the water discharge, in which the decreasing process could be divided into three phases.

The first stage (0-4 h) was a rapid settlement phase. The settlement of $30 \% \mathrm{Na}_{2} \mathrm{~S}_{2} \mathrm{O}_{8}$ reached $10.8 \mathrm{~cm}$, completing $60 \%$ of the entire settlement process, which was consistent with the law of water discharge. At the same time, the sedimentation value of other sludge samples with $0,10,20$ and $40 \% \mathrm{Na}_{2} \mathrm{~S}_{2} \mathrm{O}_{8}$ was $1.0,2.4,4.8$ and $8.9 \mathrm{~cm}$, respectively. From the second stage (about $4-24 \mathrm{~h}$ ), it could be found that the sedimentation rate of high dosage was much larger than that of low dosage. The settlement of $30 \% \mathrm{Na}_{2} \mathrm{~S}_{2} \mathrm{O}_{8}$ exceeded $99 \%$ of the total settlement. Compared with the other two stages, the settlement curve of the third stage was flat, indicating the dehydration capacity of the sludge sample was significantly reduced. At this stage, the sedimentation volume of the non-conditioned sludge remained unchanged, while the settlement amount of the conditioned sludge was only about $0.5-0.7 \mathrm{~cm}$.

Eventually, it can be easily found that the original sludge finally settled only $1.2 \mathrm{~cm}$, while the maximum sedimentation reached $18.1 \mathrm{~cm}$ when $30 \%$ sodium persulfate was added. The latter was 16 times more than the former. Furthermore, the sedimentation value of each sludge sample (containing $0,10,20,30$ and $40 \%$ sodium persulfate reagent) was $4.7,29.3,40.7,59.7$ and $50.5 \%$ of the initial height, individually. In the whole test process, the sedimentation volume of the treated sludge was extremely reduced than the original sludge, which indicated that $\mathrm{Fe}^{2+}$-activated sodium persulfate treatment could effectively accelerate the drainage consolidation of vacuum preloading.

After $\mathrm{Fe}^{2+}$-activated sodium persulfate and vacuum preloading, the volume of LS samples had changed to a certain degree, and the volume reduction ratio (reduced volume vs original volume) could be calculated to reflect the change in volume. The volume reduction ratio of the sludge sample (with $0,30 \%$ sodium persulfate reagent) was $5.3 \%$ and $56.9 \%$, respectively. The latter was 10 times than the former, which manifested that the treatment of $\mathrm{Fe}^{2+}$-activated sodium persulfate combined with vacuum preloading has a highly significant contribution to sludge volume reduction.

\subsubsection{Water content and unconfined compressive strength}

After the $\mathrm{Fe}^{2+}$-activated sodium persulfate and vacuum preloading, the surface, middle and bottom of the sludge samples were taken to test the water content. The relationship between the water content and the location was shown in Fig. 7. It was found that the original sludge's water content did not decrease obviously after $\mathrm{Fe}^{2+}$-activated sodium persulfate combined with vacuum preloading, while the moisture content with the conditioned sludge drops significantly after being conditioned by $\mathrm{Fe}^{2+}$-activated sodium persulfate. The water content (surface layer) of sludge samples with $0,10,20,30$ and $40 \% \mathrm{Na}_{2} \mathrm{~S}_{2} \mathrm{O}_{8}$ was $73.5,68.5,63.4,58.3$ and $61.4 \%$. The water content close to the surface layer dropped evidently than that in the middle and the bottom parts of the sludge samples. The general characteristics of the water content were surface layer $>$ middle $>$ bottom, which was due to the attenuation of the vacuum degree and damping of the hydraulic gradient (Wu et al., 2021b; Wu et al., 2017). Besides, the vacuum stress 
decreased with the increase of depth, causing the water content to increase (Indraratna et al., 2005; Wu et al., 2021b).

It was difficult for the vacuum degree to reach the bottom, so the moisture content of the bottom was still fairly high. In addition, bound water held a large number of pores and exhibited a low permeability, which made it difficult to discharge the water by vacuum preloading (Wu,Lin, et al., 2018a). On the other hand, Wu,Lin, et al. (2018a) pointed out that the sludge contained a lot of organic matter, easy to deform and blocked the pores and drainage channels. As a result, the formation of the upper low-permeability layer seriously affected the drainage speed of vacuum preloading (Wu,Lin, et al., 2018a). The outcomes demonstrated that the moisture content of the sludge treated by $30 \%$ sodium persulfate's reagent reached the minimum, the average water content dropped to about $59.0 \%$, much lower than the original sludge (the average water is $75.6 \%$ ). What's more, the water content of landfill sludge treated by $\mathrm{Fe}^{2+}$-activated sodium persulfate combined with vacuum preloading was less than $60 \%$, meeting the water content requirements of China (CJ/T249-2007, 2007).

Table 2 Unconfined compressive strength of the sample.

\begin{tabular}{|llllll|}
\hline Item & 1 & 2 & 3 & 4 & 5 \\
\hline $\mathrm{Na}_{2} \mathrm{~S}_{2} \mathrm{O}_{\mathbf{8}}(\%)$ & 0 & 10 & 20 & 30 & 40 \\
\hline Unconfined compressive strength $(\mathrm{kPa})$ & - & - & 28.4 & 39.2 & 32.5 \\
\hline
\end{tabular}

Note: "-" indicates that the sludge strength is too low, and the unconfined compressive value cannot be measured.

On the other hand, a UCS test was also carried out on the sludge. The UCS was measured by taking samples close to the lower surface of the sludge at room temperature with an unconfined compressive strength compression meter. The results were shown in Table 2. The original sludge and $10 \% \mathrm{Na}_{2} \mathrm{~S}_{2} \mathrm{O}_{8}$ dosage were in a fluid state, and its UCS cannot be measured. With the treatment of $\mathrm{Fe}^{2+}-$ activated sodium persulfate, the sludge was more easily dewatered, and the internal bound water was released (Luo et al., 2018). Besides, the moisture content of the LS was decreased, and the whole sludge seemed denser after $\mathrm{Fe}^{2+}$-activated sodium persulfate combining with vacuum preloading. The maximum UCS of the sludge obtained by measuring the addition of $30 \%$ sodium persulfate could reach $39.2 \mathrm{kPa}$. Furthermore, the strength with the sludge examples after $\mathrm{Fe}^{2+}$-activated sodium persulfate and vacuum preloading have been significantly advanced, and the effect was significant.

\subsubsection{Scanning electron microscopy experimental analysis}

To view the particle size changes and morphological features with the LS (Wu et al., 2021b), SEM experiments were performed on the sludge examples after combining $\mathrm{Fe}^{2+}$-activated sodium persulfate and vacuum preloading. The unconditioned sludge and the conditioned sludge $\left(30 \% \mathrm{Na}_{2} \mathrm{~S}_{2} \mathrm{O}_{8}\right)$ were compared for comparison. 
The non-conditioned sludge's structure was loose and presented a glial structure, as shown in Fig. 8(a). And, the non-conditioned sludge also contained many pores, a large specific surface area, and a certain amount of impurities, making it difficult to remove the water inside the sludge particles (Yang et al., 2015). After $\mathrm{Fe}^{2+}$-activated sodium persulfate combined with vacuum preloading, as shown in Fig. 8(b), the flocculation structure of the sludge was destroyed and wrapped together, the small particles increased significantly (Li et al., 2017) compared with Fig. 8(a), and the dehydration performance was remarkably promoted (Ruan et al., 2021). At the same time, the oxidation of sodium persulfate causes the glial structure of the sludge to be destroyed and dense. Some particles contained cracks and pores, and some particles were rearranged and combined (Shi et al., 2015). In addition, the significant increase in small particles was consistent with the results of the particle size experiment (as shown in Fig. 8(a)).

As a new technology, the combined treatment of sludge using $\mathrm{Fe}^{2+}$-activated sodium persulfate and vacuum preloading abundantly made full use of the strongly oxidizing properties of $\mathrm{Fe}^{2+}$-activated sodium persulfate and the strong dewatering efficiency of vacuum preloading, which could change the structure and microscopic properties of the sludge flocs, releasing the bound water on the surface of the extracellular polymer and the water inside the sludge cells. This kind of treatment has an improvement effect on the dewatering of LS, which was better than ordinary vacuum preloading.

\section{Conclusion}

(1) The dewatering capacity of the sludge was significantly advanced after $\mathrm{Fe}^{2+}$-activated $\mathrm{Na}_{2} \mathrm{~S}_{2} \mathrm{O}_{8}$ preconditioning, and the SRF was reduced to a minimum at 30\% dosage, in which the highest SRF reduction efficiency of LS could be reduced by approximately $98.5 \%$. Excessive addition would lead to an increase in SRF, which was inconducive to dehydration of LS.

(2) The results of the particle analysis test manifested the particle size of sludge was significantly smaller, large particles were obviously reduced. The cumulative distribution curve of LS shifted upward compared with non-conditioned sludge. The PSD of the LS mainly focused on the sand and silty groups.

(3) After Fe ${ }^{2+}$-activated $\mathrm{Na}_{2} \mathrm{~S}_{2} \mathrm{O}_{8}$ assisted vacuum preloading, the LS's maximum water output was close to $1500 \mathrm{ml}$, while that of non-conditioned was less than $100 \mathrm{ml}$. In addition, the highest UCS of the sludge treated with the method could reach $39.2 \mathrm{kPa}$. The lowest water content of LS drops from $86.9 \%$ to $58.3 \%$, and the largest water content volume was reduced by approximately $57 \%$.

(4) The SEM experiment indicated that non-conditioned sludge presented a glial structure and contained a large number of impurities. In contrast, the conditioned sludge appeared in dense clusters with cracks and part of LS's particles rearranged and combined.

\section{Declarations}

\section{Ethical Approval}


Our manuscript does not report on or involve the use of any animal or human data or tissue. Therefore, Ethical Approval is "Not applicable" in this section.

\section{Consent to Participate}

Our manuscript does not report on or involve the use of any animal or human data or tissue. Therefore, Consent to Participate is "Not applicable" in this section.

\section{Consent to Publish}

Our manuscript does not contain data from any individual person. Therefore, Consent to Publish is "Not applicable" in this section.

\section{Authors Contributions}

Yajun Wu: Project administration, Resources, Writing - review \& editing, Supervision.

Xingtao Zhang: Investigation, Data curation, Formal analysis, Writing - original draft.

Xudong Zhang: Conceptualization, Data curation, Formal analysis, Writing - original draft, Supervision.

Haiqiang Zhang: Conceptualization, Data curation, Writing - review \& editing.

Yaoyi Wang: Conceptualization, Investigation, Writing - review \& editing.

Peng Ye: Conceptualization, Data curation, Writing - review \& editing.

All authors read and approved the final manuscript."

\section{Funding}

The authors are grateful for the financial support for the study presented in this paper from the National Natural Science Foundation of China (Grant No. 41772303), the Shanghai Sailing Program (Grant No. 19YF1415500).

\section{Competing Interests}

The authors declare that they have no known competing financial interests or personal relationships that could have appeared to influence the work reported in this this section.

\section{Availability of data and materials}

Our manuscript does not contain any data, therefore, it is 'Not applicable' in this section.

\section{References}


Ahmad, M., Teel, A. L., and Watts, R. J., 2013. Mechanism of Persulfate Activation by Phenols. Environmental Science and Technology. 47(11), 5864-71. http://dx.doi.org/10.1021/es400728c.

Alami, D. E., Monlau, F., Abdelouahdi, K., Oukarroum, A., and Barakat, A., 2019. Pretreatment and codigestion of wastewater sludge for biogas production: Recent research advances and trends. Renewable and Sustainable Energy Reviews. 114. http://dx.doi.org/10.1016/j.rser.2019.109287.

Becerra, Fyg., Acosta, E. J., and Allen, D. G., 2010. Alkaline extraction of wastewater activated sludge biosolids. Bioresource Technology. 101, 6972-80. http://dx.doi.org/10.1016/j.biortech.2010.04.021.

Buxton, G. V., 1999. The reactivity of chlorine atoms in aqueous solution. Physical Chemistry Chemical Physics. 1(1), 269-73. http://dx.doi.org/10.1039/a807808d.

Cai, C., Zhang, H., Zhong, X., and Hou, L. W., 2015. Ultrasound enhanced heterogeneous activation of peroxymonosulfate by a bimetallic Fe-Co/SBA-15 catalyst for the degradation of Orange II in water. Journal of Hazardous Materials. 283, 70-79. http://dx.doi.org/10.1016/j.jhazmat.2014.08.053.

Chen, Y. G., Yang, H. Z., and Gu, G., 2001. Effect of acid and surfactant treatment on activated sludge dewatering and settling. Water Research. 35(11), 2615-20. http://dx.doi.org/10.1016/s00431354(00)00565-0

CJ/T249-2007, 2007. Disposal of Sludge From Municipal Wastewater Treatment Plant: Sludge Quality for Co-landfilling. Ministry of Building and Construction, P.R. China.

Feng, X., Deng, J. C., Lei, H. Y., Bai, T., Fan, Q. J., and Li, Z. X., 2009. Dewaterability of waste activated sludge with ultrasound conditioning. Bioresource Technology. 99, 1074-

81. http://dx.doi.org/10.1016/j.biortech.2008.07.055.

Guan, Y.H., Ma, J., Li, X.C., Fang, J.Y., and Chen, L.W., 2011. Influence of pH on the Formation of Sulfate and Hydroxyl Radicals in the UV/Peroxymonosulfate System. Environmental Science \& Technology. 45, 9308-14. http://dx.doi.org/10.1021/es2017363.

Hoadley, A. F. A., Qi, Y., and Thapa, K. B., 2011. Application of filtration aids for improving sludge dewatering properties - A review. ChemInform. 42(41), 373-84. http://dx.doi.org/10.1002/chin.201141268.

Indraratna, B., Sathananthan, I., Rujikiatkamjorn, C., and Balasubramaniam, A.S., 2005. Analytical and numerical modeling of soft soil stabilized by prefabricated vertical drains incorporating vacuum preloading. International Journal of Geomechanics. 5, 114-24. http://dx.doi.org/10.1061/(ASCE)15323641(2005) 5:2(114).

Kim, M. S., Lee, K. M., Kim, H. E., Lee, H. J., Lee, C. S., and Lee, C. H., 2016. Disintegration of waste activated sludge by thermally-activated persulfates for enhanced dewaterability. Environmental Science \& Technology. 50(13), 7106. http://dx.doi.org/10.1021/acs.est.6b00019. 
Li, H. X., Wang, Y. L., and Zheng, H. L., 2017. Variations of moisture and organics in activated sludge during $\mathrm{Fe}^{0} / \mathrm{S}_{2} \mathrm{O}_{8}{ }^{2-}$ conditioning-horizontal electro-dewatering process. Water Research. 129, 8393. http://dx.doi.org/10.1016/j.watres.2017.11.006.

Li, Q. Y., 2020. Current situation and developmenttrend of urban sludge disposal in China based on carbon emission reduction analysis. Harbin Institute of Technology.

Liang, C. J., Lee, I. L., Hsu, I. Y., Liang, C. P., and Lin, Y. L., 2008. Persulfate oxidation of trichloroethylene with and without iron activation in porous media. Chemosphere. 70(3), 426-

35. http://dx.doi.org/10.1016/j.chemosphere.2007.06.077.

Liang, C., Wang, Z. S., and Bruell, C. J., 2007. Influence of $\mathrm{pH}$ on persulfate oxidation of TCE at ambient temperatures. Chemosphere. 66(1), 106-13. http://dx.doi.org/10.1016/j.chemosphere.2006.05.026.

Lin, W., Zhan, X., Zhan, T., Chen, Y., Jin, Y., and Jiang, J., 2014. Effect of $\mathrm{FeCl}_{3}$-conditioning on consolidation property of sewage sludge and vacuum preloading test with integrated pvds at the changan landfill, China. Geotextiles \& Geomembranes. 42, 181-

90. http://dx.doi.org/10.1016/j.geotexmem.2013.12.008.

Lo, Irene M. C., Lai, Keith C. K., and Chen, G. H., 2001. Salinity effect on mechanical dewatering of sludge with and without chemical conditioning. Environmental ence \& Technology. 35(23), 4691. http://dx.doi.org/10.1021/es010834x.

Luo, J.Y., Zhang, Q., Wu, L.J., Feng, Q., Fang, F., Xue, Z.X., Li, C., and Cao, J.S., 2018. Improving anaerobic fermentation of waste activated sludge using iron activated persulfate treatment. Bioresource Technology. 268, 68-76. http://dx.doi.org/10.1016/j.biortech.2018.06.080.

Mowla, D., Tran, H. N., and Allen, D. G., 2013. A review of the properties of biosludge and its relevance to enhanced dewatering processes. Biomass \& Bioenergy. 58, 365-

78. http://dx.doi.org/10.1016/j.biombioe.2013.09.002.

Raynaud, M., Vaxelaire, J., Olivier, J., Dieude-Fauvel, E., and Baudez, J., 2012. Compression dewatering of municipal activated sludge:Effects of salt and pH. Water Research. 46(14), 444856. http://dx.doi.org/10.1016/j.watres.2012.05.047

Ren, W., Zhou, Z., Zhu, Y., Jiang, L., Wei, H., Niu, T., Fu, P., Qiu, Z., and 2015. Effect of sulfate radical oxidation on disintegration of waste activated sludge. International Biodeterioration \& Biodegradation. $104,384-90$

http://dx.doi.org/10.1016/j.ibiod.2015.07.008.

Ruan, S. Y., Deng, J., Cai, A. H., Chen, S. N., and Li, X. Y., 2021. Improving dewaterability of waste activated sludge by thermally-activated persulfate oxidation at mild temperature. Journal of Environmental 
Management. 281(47), 111899. http://dx.doi.org/10.1016/j.jenvman.2020.111899.

Sheng, G. P., Yu, H. Q., and Li, X. Y., 2010. Extracellular polymeric substances (EPS) of microbial aggregates in biological wastewater treatment systems: A review. Biotechnology Advances. 28, 88294. http://dx.doi.org/10.1016/j.biotechadv.2010.08.001.

Shi, Y., Yang, J., Yu, W., Zhang, S., and Hu, J., 2015. Synergetic conditioning of sewage sludge via $\mathrm{Fe}^{2+}$ /persulfate and skeleton builder: Effect on sludge characteristics and dewaterability. Chemical Engineering Journal. 270, 572-81. http://dx.doi.org/10.1016/j.cej.2015.01.122.

Wei, L., Xia, X., Zhu, F., Li, Q., Xue, M., Li, J., and Zhao, Q., 2020. Dewatering efficiency of sewage sludge during $\mathrm{Fe}^{2+}$-activated persulfate oxidation: Effect of hydrophobic/hydrophilic properties of sludge EPS. Water Research. 115903. http://dx.doi.org/10.1016/j.watres.2020.115903

Wei, L., Xia, X., Zhu, F., Li, Q., and Zhao, Q., 2020. Dewatering efficiency of sewage sludge during $\mathrm{Fe}^{2+}$ activated persulfate oxidation: Effect of hydrophobic/hydrophilic properties of sludge EPS. Water Research. 181, 115903. http://dx.doi.org/10.1016/j.watres.2020.115903.

Wu, W., Zhou, Z., Yang, J., Chen, G., Yao, Jie, Tu, C., Zhao, X., and Wu, Z., 2019. Insights into conditioning of landfill sludge by $\mathrm{FeCl}_{3}$ and lime. Water Research. 160(SEP.1), 167-

77. http://dx.doi.org/10.1016/j.watres.2019.05.071.

Wu, Y. J., Lin, Z. X., Kong, G. Q., and Hu, T., 2018a. Treatment of municipal sludge by Fenton oxidation combined vacuum preloading. Environmental Science \& Pollution Research International. http://dx.doi.org/10.1007/s11356-018-1736-5.

Wu, Y. J., Tang, X., Cui, C., Wang, G., and Hu, T., 2018a. Experimental study on characteristics of vacuum consolidation of municipal sludge. Journal of Southeast University (Natural Science Edition). 48(004).

Wu, Y. J., Xu, Y., Zhang, X. D., Lu, Y. T., Chen, G., Wang, X. D., and Song, B. J., 2021b. Experimental study on vacuum preloading consolidation of landfill sludge conditioned by Fenton's reagent under varying filter pore sizes. Geotextiles and Geomembranes. 49(1), 109-

21. http://dx.doi.org/10.1016/j.geotexmem.2020.09.008.

Wu, Y. J., Xu, Y., Zhang, X. D., Lu, Y. T., and Ji, J. W., 2020. Experimental study on treating landfill sludge by preconditioning combined with vacuum preloading: Effects of freeze-thaw and $\mathrm{FeCl}_{3}$ preconditioning. Science of the Total Environment. 747, 141092. http://dx.doi.org/10.1016/j.scitotenv.2020.141092.

Wu, Y. J., Zhang, X. T., Zhang, X. D., Xu, Y., and Zhang, H. Q., 2021c. Novel insights into enhanced dewaterability and consolidation characteristics of landfill sludge and fresh sludge conditioned by $\mathrm{Fe}^{2+}$ activated sodium persulfate. Journal of Environmental Management. 296, 113196. http://dx.doi.org/10.1016/j.jenvman.2021.113196. 
Wu, Y., Kong, G., Lu, Y., and Sun, D., 2017. Experimental study on vacuum preloading with flocculation for solid-liquid separation in waste slurry. Geomechanics and Engineering. 13, 319-

31. http://dx.doi.org/10.12989/gae.2017.13.2.319.

Xu Y., Wu Y., and Zhang X., 2021. Effects of freeze-thaw and chemical preconditioning on the consolidation properties and microstructure of landfill sludge. Water Research. 117249.

Yang, G., Zhang, G. M., and Wang, H. C., 2015. Current state of sludge production, management, treatment and disposal in China. Water Research. 78, 60-73. http://dx.doi.org/10.1016/j.watres.2015.04.002.

Yuan, H. P., Yan, X. F., Yang, C. F., and Zhu, N. W., 2011. Enhancement of waste activated sludge dewaterability by electro-chemical pretreatment. Journal of Hazardous Materials. 187(1-3), 8288. http://dx.doi.org/10.1016/j.jhazmat.2010.12.106.

Zhan, X. J., Lin, W. A., Zhan, L. T., and Chen, Y. M., 2015. Field implementation of $\mathrm{FeCl}_{3}$-conditioning and vacuum preloading for sewage sludge disposed in a sludge lagoon: a case study. Geosynthetics International. 22(4), 327-38. http://dx.doi.org/10.1680/gein.15.00015.

Zhan, X. J., Lin, W. A., Zhan, L. T., Luo, X. Y., and Chen, Y. M., 2013. Model test study of vacuum preloading on municipal sludge. Rock and soil mechanics. 34, 88-96.

Zhang, W., Yang, P., Yang, X., Chen, Z., and Wang, D., 2015. Insights into the respective role of acidification and oxidation for enhancing anaerobic digested sludge dewatering performance with Fenton process. Bioresour Technol. 181, 247-53. http://dx.doi.org/10.1016/j.biortech.2015.01.003.

Zhang, X. D., Lu, Y. T., Wu, Y. J., and Vuong, V. Q., 2020. Insight into conditioning landfill sludge with ferric chloride and a Fenton reagent: Effects on the consolidation properties and advanced dewatering.

Chemosphere. 252, 126528. http://dx.doi.org/10.1016/j.chemosphere.2020.126528.

Zhang, X., Wu, Y., Zhai, E., and Ye, P., 2021a. Coupling analysis of the heat-water dynamics and frozen depth in a seasonally frozen zone. Journal of Hydrology. 593, 125603. http://dx.doi.org/10.1016/j.jhydrol.2020.125603.

Zhang, X., Zhai, E., Wu, Y., Sun, D., and Lu, Y., 2021b. Theoretical and Numerical Analyses on HydroThermal-Salt-Mechanical Interaction of Unsaturated Salinized Soil Subjected to Typical Unidirectional Freezing Process. International Journal of Geomechanics. 21(7), 04021104. http://dx.doi.org/10.1061/(ASCE)GM.1943-5622.0002036.

Zhen, G., Lu, X., Li, Y., Zhao, Y., Wang, B., Chai, X., Niu, D., and Cao, X., 2012. Novel insights into enhanced dewaterability of waste activated sludge by $\mathrm{Fe}(\mathrm{II})$-activated persulfate oxidation. Bioresource Technology. 119. http://dx.doi.org/10.1016/j.biortech.2012.05.115. 
Zhou, X., Wang, Q., Jiang, G., Liu, P., and Yuan, Z., 2015. A novel conditioning process for enhancing dewaterability of waste activated sludge by combination of zero-valent iron and persulfate. Bioresource Technology. 185, 416-20. http://dx.doi.org/10.1016/j.biortech.2015.02.088.

\section{Figures}

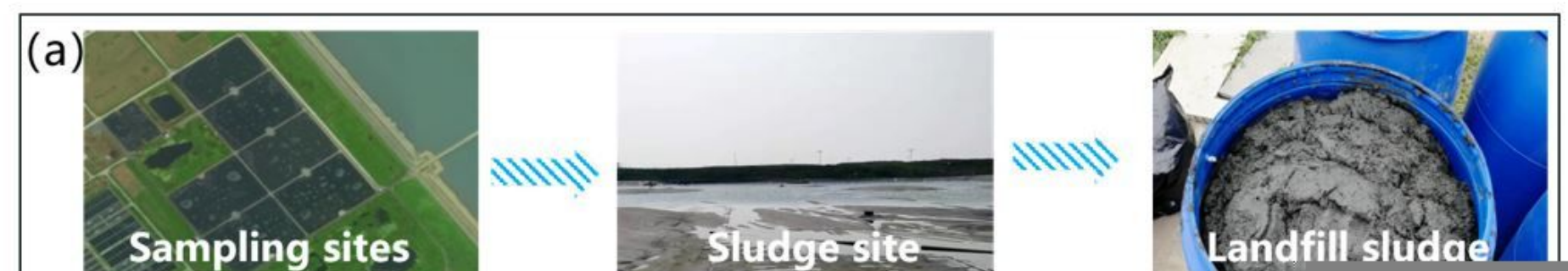

Figure 1

The flow chart of the experiment 
Figure 2

Location map of sludge sampling (a. MAP of sampling points; b. sludge landfill).
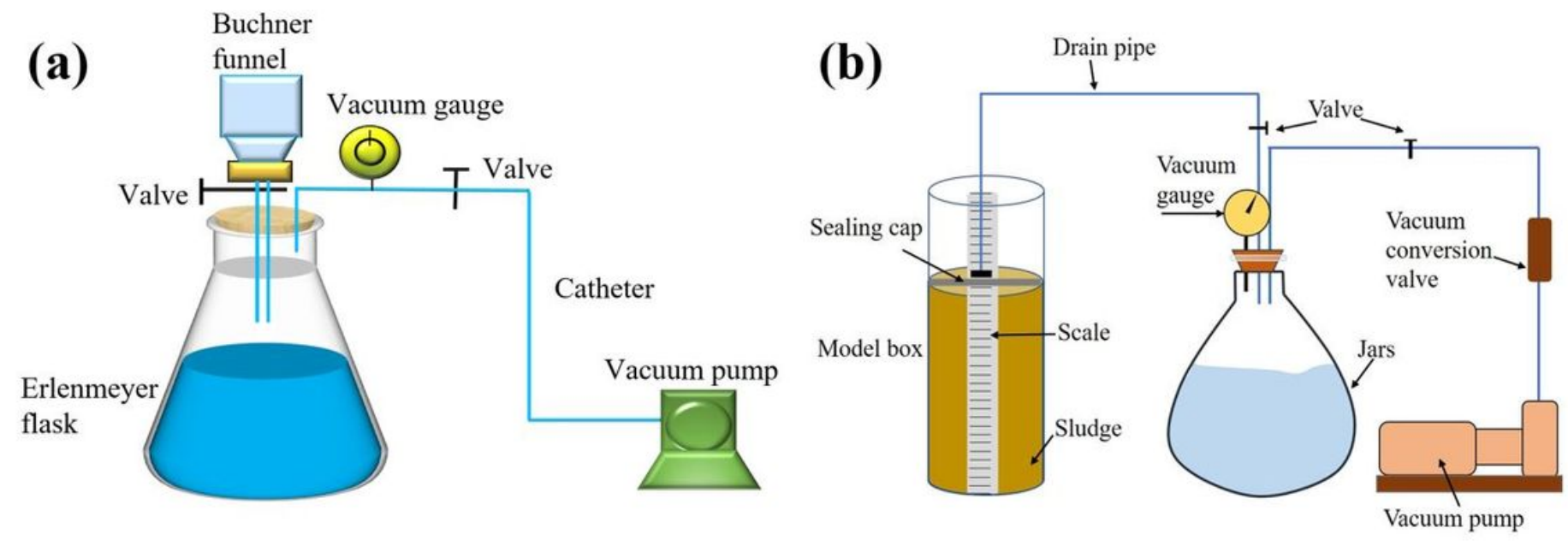

Figure 3

Schematic representation of the device (a. Vacuum filtration experiment device; b. Vacuum preloading experiment device). 
Figure 4

Schematic diagram of vacuum filtration test results (a. SRF and SRF reduction efficiency; b. pH and SRF reduction efficiency; c. Organic matter content; $d$. Water content). 
(a)

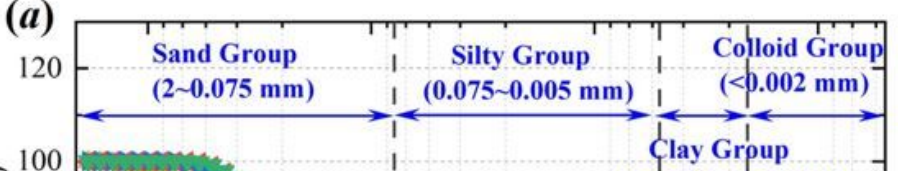

\begin{tabular}{|c|c|c|c|c|c|}
\hline b) & $T$ & TT & 11 & $T$ & 111 \\
\hline & $\begin{array}{l}\text { Sand Group } \\
(2 \sim 0.075 \mathrm{~mm})\end{array}$ & $\begin{array}{l}1 \\
1\end{array}$ & $\begin{array}{c}\text { Silty Group } \\
(0.075 \sim 0.005 \mathrm{~mm})\end{array}$ & 1 & $\begin{array}{c}\text { Colloid Group } \\
(<0.002 \mathrm{~mm})\end{array}$ \\
\hline
\end{tabular}

\section{Figure 5}

Particle analysis test (a. Cumulative percentage with particle size; b. Percentage content with particle size). 
(a)

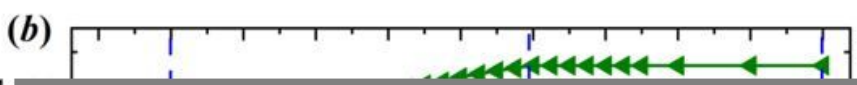

Figure 6

Test results of vacuum preloading model box (a. Vacuum level; b. Water discharge; c. Drainage rate; $d$. Settlement). 


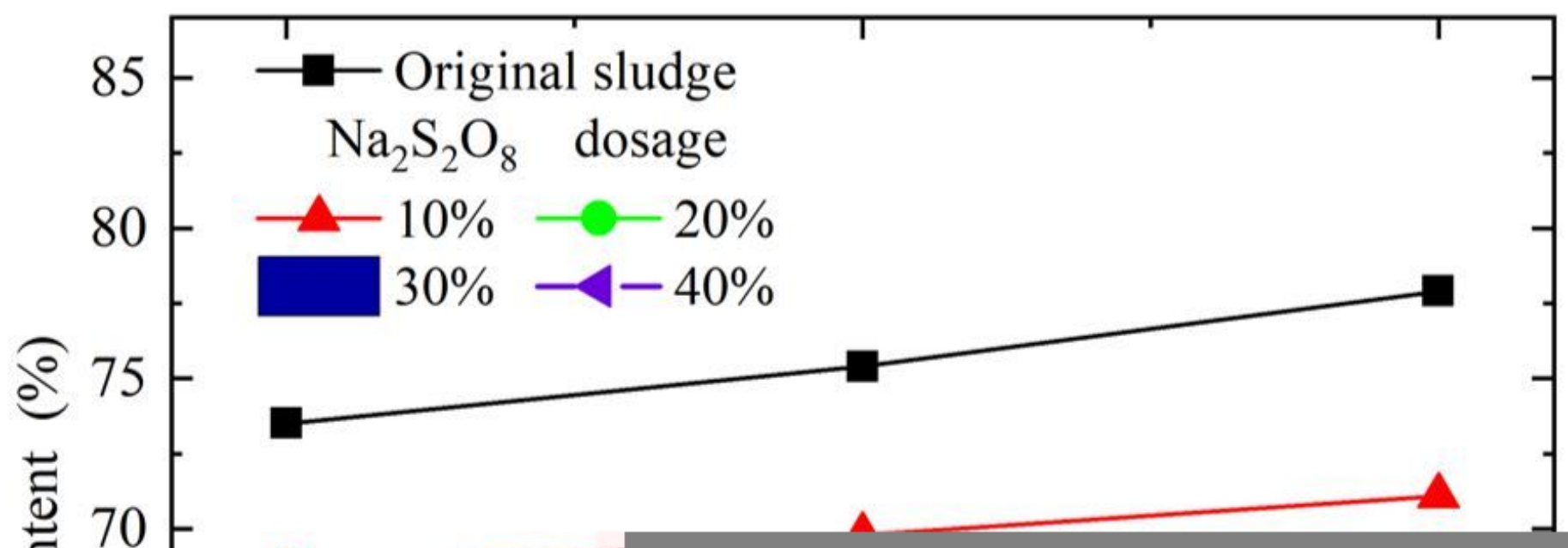

Figure 7

Water content after the vacuum preloading experiments.

Figure 8

SEM experiment results (a. Unconditioned sludge; b. Sludge conditioned by the $30 \% \mathrm{Na} 2 \mathrm{~S} 2 \mathrm{O} 8$ dosage). 